\title{
BMJ Open Respiratory Research \\ Can postural OSA be usefully identified from its severity alone?
}

\author{
Aihem Johar, Chris D Turnbull, John R Stradling
}

To cite: Johar A, Turnbull CD, Stradling JR. Can postural OSA be usefully identified from its severity alone?. BMJ Open Resp Res 2017;4:e000259. doi:10.1136/ bmjresp-2017-000259

Received 31 October 2017 Revised 28 November 2017 Accepted 29 November 2017

\section{(a) CrossMark}

NIHR Oxford Biomedical Research Centre and Oxford Centre for Respiratory Medicine, Oxford University and Oxford University Hospitals NHS Foundation Trust, Churchill Hospital, Oxford, UK

Correspondence to Professor John R Stradling; John.Stradling@ouh.nhs.uk

\section{ABSTRACT}

Introduction When obstructive sleep apnoea (OSA) does not occur throughout sleep, there must be factors influencing its presence or absence. These are most likely to be sleep stage, posture and presleep alcohol, among others. We hypothesised that as OSA severity increases, the likelihood of postural OSA (POSA) would also decrease. Methods Laboratory sleep studies of 39 patients with OSA were manually reviewed to calculate supine and non-supine oxygen desaturation indices (ODI). The usual definition for POSA was used, a ratio of supine to nonsupine ODI of $\geq 2$.

Results The mean age was 53.2 (SD 12.4) years, the body mass index was 35.0 (SD 8.9 ) $\mathrm{kg} / \mathrm{m}^{2}$ and $74 \%$ were male. The median supine ODI was 54.3 (IQR 25.7-73.5) and non-supine ODI was 18.7 (IQR 8.6-38.4). The overall prevalence of POSA was $56 \%$. The prevalence of POSA for ODls of $<40$ was $68 \%$, and $35 \%$ if $\geq 40$.

Conclusions An ODI $\geq 40$, compared with $<40$, halved the likelihood of POSA from $68 \%$ to $35 \%$. Although there is clearly a relationship between overall ODI and POSA, it is not strong enough to diagnose an individual with POSA. However the relationship provides a useful way to prescreen trial subjects to enrich for POSA.

\section{INTRODUCTION}

When severe obstructive sleep apnoea (OSA) is present continuously throughout the night, its presence is unlikely to depend on such variables as sleep state, posture or presleep alcohol. As the all-night oxygen desaturation index (ODI) falls from 60 to, say, 30 , usually this does not mean that apnoeas are now $2 \mathrm{~min}$ long, rather than $1 \mathrm{~min}$, but that there are apnoeas (with the usual cycle time of about a minute) for only half the sleep time. Supine position clearly worsens OSA in many, due to increased compliance and collapsibility of the pharynx. ${ }^{1}$ This increase in collapsibility is thought to be due to the direct gravitational effects of the mandible on the upper airway, and indirectly to a reduced functional residual capacity when supine, reducing the caudal traction on the pharyngeal walls, and thus reducing the bracing effect from such traction. ${ }^{2}$ Postural treatments for OSA have been used for many years, ${ }^{3}$ and their popularity has increased recently with the introduction of posture-control devices

\section{Key messages}

As the severity of obstructive sleep apnoea increases, the presence of a postural component decreases.

> Subjects with oxygen desaturation indices under $40 /$ hour have double the prevalence of postural obstructive sleep apnoea compared with indices above 40 (68\% vs $35 \%)$.

that are somewhat more sophisticated than the tennis-ball-in-the-back-of-the-pyjamas approach. ${ }^{4}$ It is usually argued that a patient should have significant postural dependency to make a trial of such a treatment worthwhile. The exact definition of postural OSA (POSA) varies, ${ }^{5}$ but most commonly it is arbitrarily defined as a supine to non-supine ratio in the apnoea/hypopnoea index (AHI) or ODI of $\geq 2$. With a view to potential efficacy of treatments, some have argued that the non-supine AHI should also be $<5$ to be defined as POSA. ${ }^{6}$ There are very few robust data on postural therapies for OSA, with no placebo-controlled trials reporting longer term symptom-based primary outcomes. ${ }^{7}$ Such multicentre trials in ordinary clinical units are needed ${ }^{7}$ and will require simple recruitment strategies if they are to be clinically useful. We wondered if the severity of OSA on its own could be usefully used to prescreen patients for entry into such trials of POSA therapy, since earlier studies have suggested a falling off of POSA prevalence as the AHI increases. ${ }^{6}$

\section{METHODS}

Fifty clinical sleep studies (VISI-Lab, Stowood Scientific Instruments, Oxford, UK) between May and July 2016 were sequentially selected from patients diagnosed with OSA. Studies were excluded if technically inadequate, or from patients with significant associated central sleep apnoea (CSA) or hypoventilation, an $\mathrm{ODI}<5$, or those with $<30$ min of either supine or non-supine sleep. The remaining sleep studies were carefully reviewed to calculate the ODI, both supine and non-supine, 


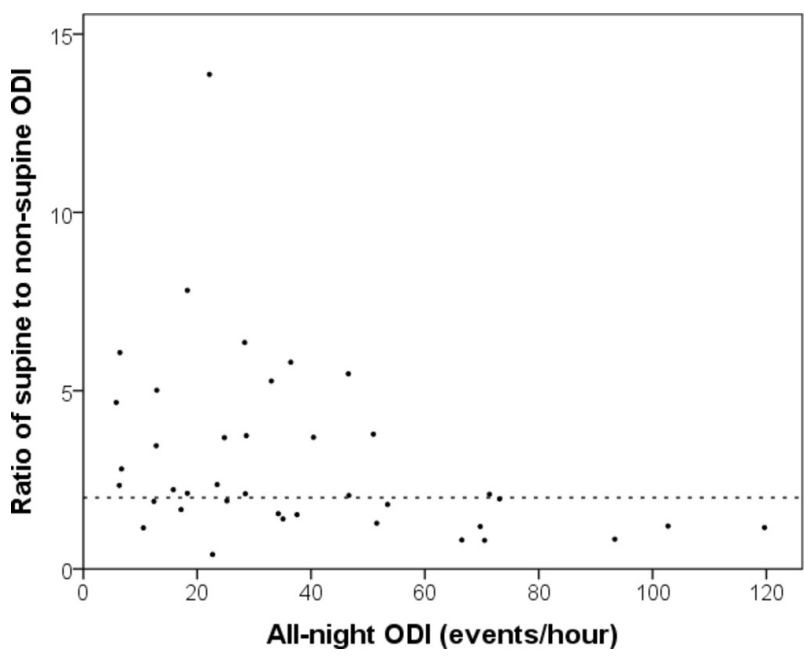

Figure 1 Relationship between all-night oxygen desaturation index (ODI) and the ratio of supine to nonsupine ODI. Horizontal line at a ratio of 2 is the conventional definition of postural obstructive sleep apnoea.

using video recording to accurately define posture. The ratio of supine to non-supine ODI was calculated and plotted against the all-night ODI. In addition, the prevalence of a supine to non-supine ratio of $\geq 2$ was calculated for the two groups, depending on whether the all-night diagnostic ODI was $<40$ or $\geq 40$.

\section{RESULTS}

Forty-six out of 50 sleep studies were technically satisfactory for this analysis. Three were further excluded due to hypoventilation or CSA, three due to $<30 \mathrm{~min}$ of supine sleep and one due to an all-night ODI $<5$, leaving 39 for the final analysis. The mean age of this study group was 53.2 (SD 12.4) years, the body mass index was 35.0 (SD 8.9) $\mathrm{kg} / \mathrm{m}^{2}$ and $74 \%$ were male. The median all-night ODI was 28.6 (IQR 17.2-51.4), supine ODI was 54.3 (IQR 25.7-73.5) and non-supine ODI was 18.7 (IQR 8.6-38.4). The clear relationship between the all-night ODI and the ratio of supine to non-supine ODI is shown in figure 1 (Spearman's rank correlation, $-0.44, \mathrm{P}<0.005)$. Taking the arbitrary definition for POSA as a ratio of $\geq 2$, the overall prevalence was $56 \%$. If the all-night ODI was $<40$, then the prevalence of POSA was $68 \%$, and if $\geq 40$ then the prevalence was $35 \%$. The prevalence of POSA when the all-night ODI is over 60 appears much smaller (figure 1), but our study numbers do not allow a robust estimate.

\section{DISCUSSION AND CONCLUSIONS}

The overall prevalence of POSA was $56 \%$, in line with previous reports. ${ }^{8}$ As expected, the likelihood of having POSA increased as the ODI fell, such that if the all-night ODI was $<40$, then the prevalence was almost double $(68 \%)$ that of those with an all-night ODI $\geq 40(35 \%)$. At the conventional ODI cut-off point for mild/moderate versus severe OSA of 30, the prevalences of POSA in the mild/moderate and severe groups were $75 \%$ and $37 \%$, respectively. The $32 \%$ prevalence of non-POSA in those with an all-night ODI of $<40$ is presumably due to other factors that only provoke OSA for part of the night, such as rapid-eye-movement sleep. Thus the diagnostic ODI from a sleep study, where posture is not routinely measured, could be used to enrich the likelihood of finding POSA when, for example, screening a patient for entry into a randomised controlled trial of POSA therapy. However, at a clinical level, it may not be useful since, even at ODI values over 40, there is still a one-third chance that a patient will have POSA, using the conventional 2:1 supine to non-supine definition.

Contributors All authors have made major contributions to this work, have reviewed the final version and take joint responsibility for the content.

Competing interests None declared.

Provenance and peer review Not commissioned; externally peer reviewed. Data sharing statement The data for this study are freely available from the senior author.

Open Access This is an Open Access article distributed in accordance with the Creative Commons Attribution Non Commercial (CC BY-NC 4.0) license, which permits others to distribute, remix, adapt, build upon this work non-commercially, and license their derivative works on different terms, provided the original work is properly cited and the use is non-commercial. See: http://creativecommons.org/ licenses/by-nc/4.0/

(C) Article author(s) (or their employer(s) unless otherwise stated in the text of the article) 2017. All rights reserved. No commercial use is permitted unless otherwise expressly granted.

\section{REFERENCES}

1. Joosten SA, Edwards BA, Wellman A, et al. The effect of body position on physiological factors that contribute to obstructive sleep apnea. Sleep 2015;38:1469-78.

2. Joosten SA, Sands SA, Edwards BA, et al. Evaluation of the role of lung volume and airway size and shape in supine-predominant obstructive sleep apnoea patients. Respirology 2015;20:819-27.

3. Cartwright RD, Lloyd S, Lilie J, et al. Sleep position training as treatment for sleep apnea syndrome: a preliminary study. Sleep 1985;8:87-94.

4. Levendowski DJ, Seagraves S, Popovic D, et al. Assessment of a neck-based treatment and monitoring device for positional obstructive sleep apnea. J Clin Sleep Med 2014;10:863-71.

5. Frank MH, Ravesloot MJ, van Maanen JP, et al. Positional OSA part 1: towards a clinical classification system for position-dependent obstructive sleep apnoea. Sleep Breath 2015;19:473-80.

6. Mador MJ, Kufel TJ, Magalang UJ, et al. Prevalence of positional sleep apnea in patients undergoing polysomnography. Chest 2005;128:2130-7.

7. Barnes H, Edwards BA, Joosten SA, et al. Positional modification techniques for supine obstructive sleep apnea: A systematic review and meta-analysis. Sleep Med Rev 2017;36:107-15.

8. Richard W, Kox D, den Herder C, et al. The role of sleep position in obstructive sleep apnea syndrome. Eur Arch Otorhinolaryngol 2006;263:946-50. 